\title{
Queering Outer Space
}

\author{
Michael P. Oman-Reagan \\ Department of Anthropology \\ Memorial University of Newfoundland
}

\begin{abstract}
:
How can queer and other minority or marginalized people stake a claim in human futures in space? This paper reflects on the challenges, opportunities, scenarios, and interventions involved as we try to queer the increasingly corporate and military human exploration of and engagement with outer space. I suggest that we must go further than academically interrogating the military and corporate narratives of space "exploration" and "colonization." We must also water, fertilize, and tend the seeds of alternative visions of possible futures in space, not only seeking solutions to earthly problems of the moment, but actively queering outer space and challenging the future to be even more queer.
\end{abstract}

Keywords: Queer Theory, Space, Anthropology, Colonialism, Mars, SETI

\section{Please Cite as:}

Oman-Reagan, Michael P. 2015. "Queering Outer Space.” SocArXiv, Open Science Framework. Manuscript, submitted January 22, 2017. osf.io/preprints/socarxiv/mpyk6/

\section{It's time to queer outer space.}

Since the Space Shuttle program was retired in 2011, the U.S. space agency NASA has turned over much of the work on space transportation to private corporations and the "commercial crew" program. As venture capitalist space entrepreneurs and aerospace contractors compete to profit from space exploration, we're running up against increasingly conflicting visions for human futures in outer space (Wright and Oman-Reagan 2017). Narratives of military tactical dominance alongside "NewSpace" ventures like asteroid mining projects call for the defense, privatization, and commodification of space and other worlds, framing space as a resource-rich "frontier" to be "settled" in what amounts to a new era of colonization (Anker 2005; Redfield 2000; Valentine 2012, Wright and Oman-Reagan 2017). 


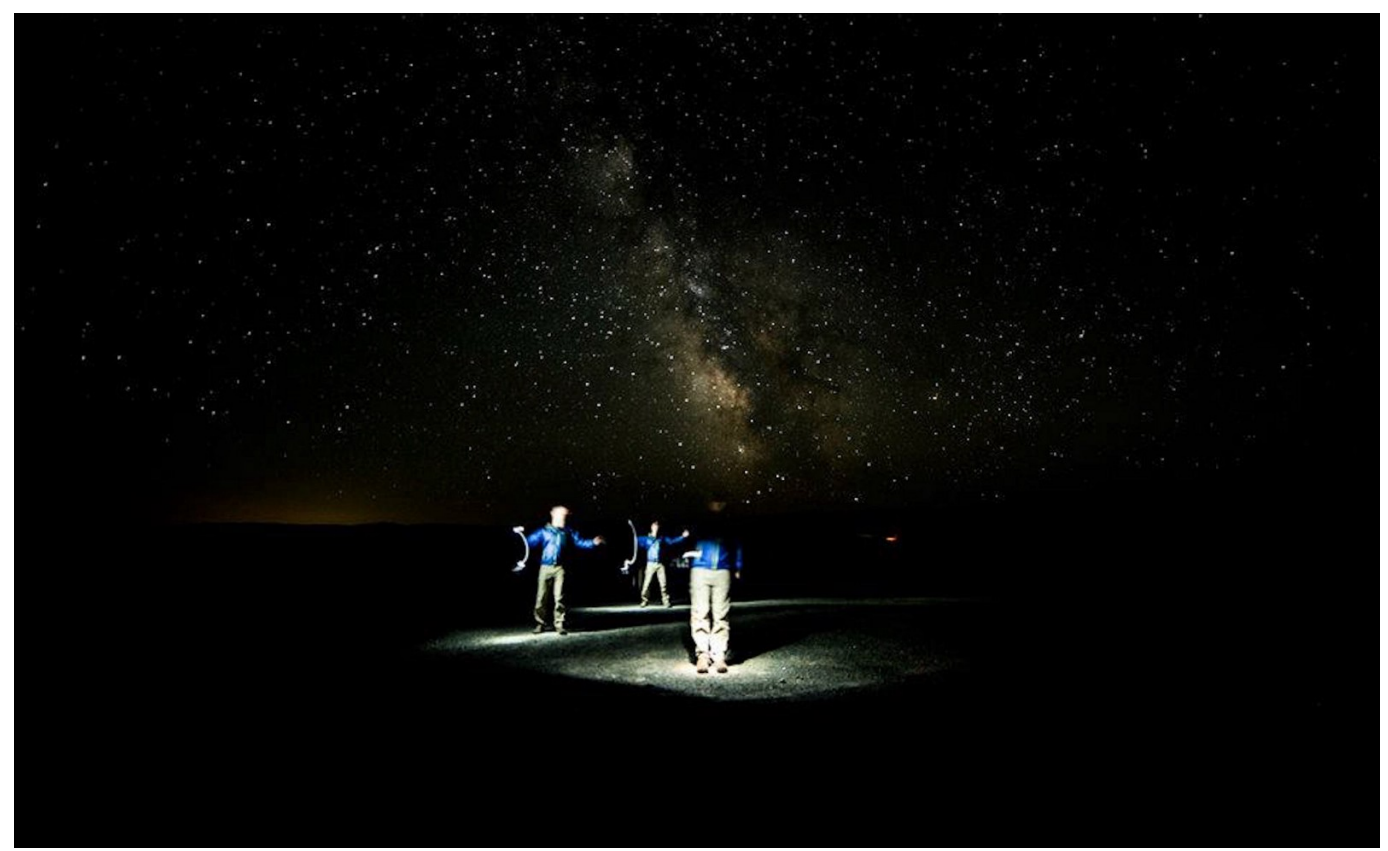

Figure 1: Multiple-exposure-me under the Milky Way in Eastern Oregon. (photo: Nicholas Siegrist)

However, from at least the 1970s, some space scientists have challenged this trajectory of resource extraction, neo-colonialism, and reproduction of earthly political economies with alternative visions of the future (McCray 2012). Today's “visionary" space scientists imagine space exploration as a source of transformative solutions to earthly problems such as climate change, economic inequality, conflict, and food insecurity (Grinspoon 2003; Hadfield 2013; Sagan 1994; Shostak 2013; Tyson 2012; Vakoch 2013).

As a PhD student in anthropology I'm conducting my research in this area but here I want to argue that we must go even further than academically interrogating the military and corporate narratives of space "exploration" and "colonization." We must water, fertilize, and tend the seeds of alternative visions of possible futures in space, not only seeking solutions to earthly problems which are trendy at the moment, but actively queering outer space and challenging the future to be even more queer. 


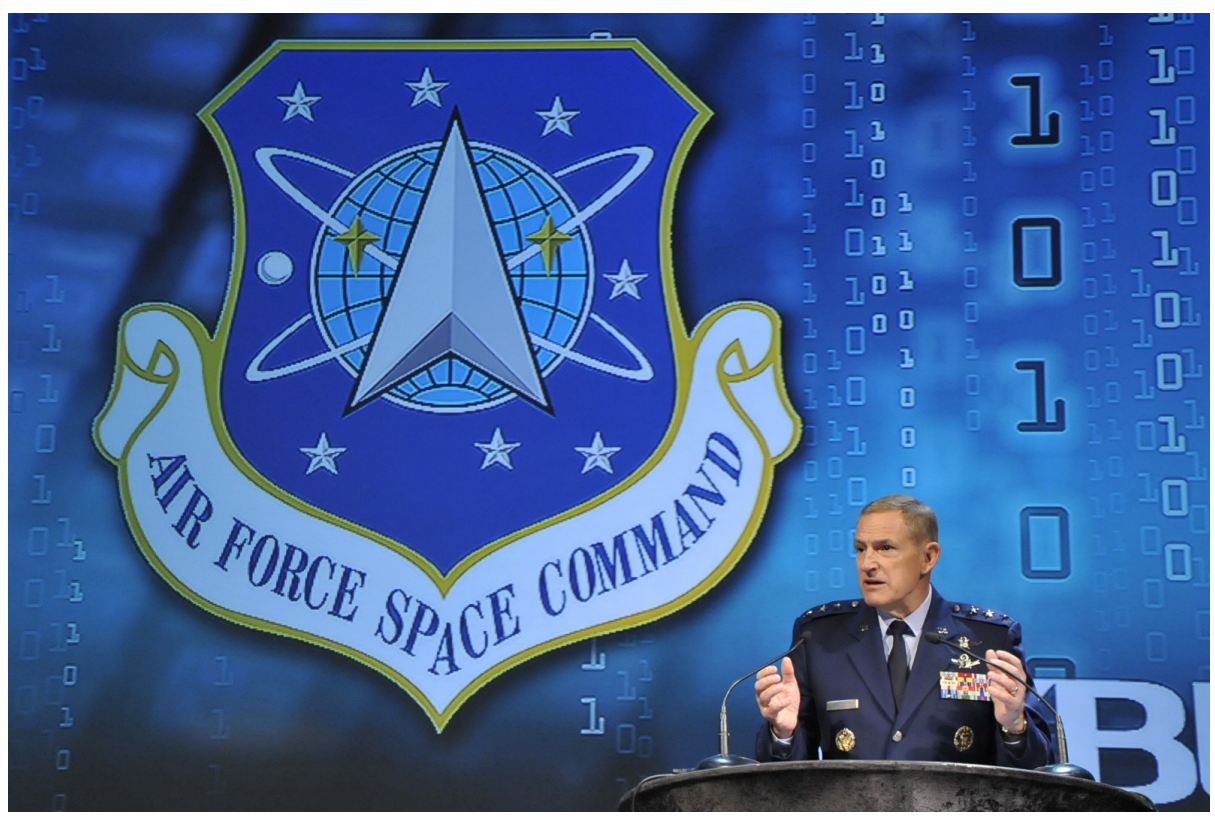

Figure 2: All your space are belong to us. (Air Force Space Command)

I'm queering the word queer here-I want to use it to call for more people of color, more indigenous voices, more women, more LGBTQetc., more alternative voices to the dominant narratives of space programs and space exploration. I want to use queer to stand in for a kind of intersectionality that I can speak from without appropriating or speaking on behalf of others, as a queer person. So by saying queer, I'm not trying to subsume other identities and struggles into the queer ones, but calling out to them and expressing solidarity and respect for difference in joint struggle, I'm inviting you all.

I also don't want to write "intersectionalize" outer space but it's basically what I mean. So, when I use it here queer is not marriage equality and the HRC (Human Rights Campaign or Hillary Rodham Clinton, either works) and heteronormativity mapped onto cis, white, gay, male characters ready for a television show. It's also not me with my own limited corner of queer, minority, and disability experience. Queer is deeply and fully queer. As Charlie, an awesome person I follow on twitter calls it: "queer as heck." 


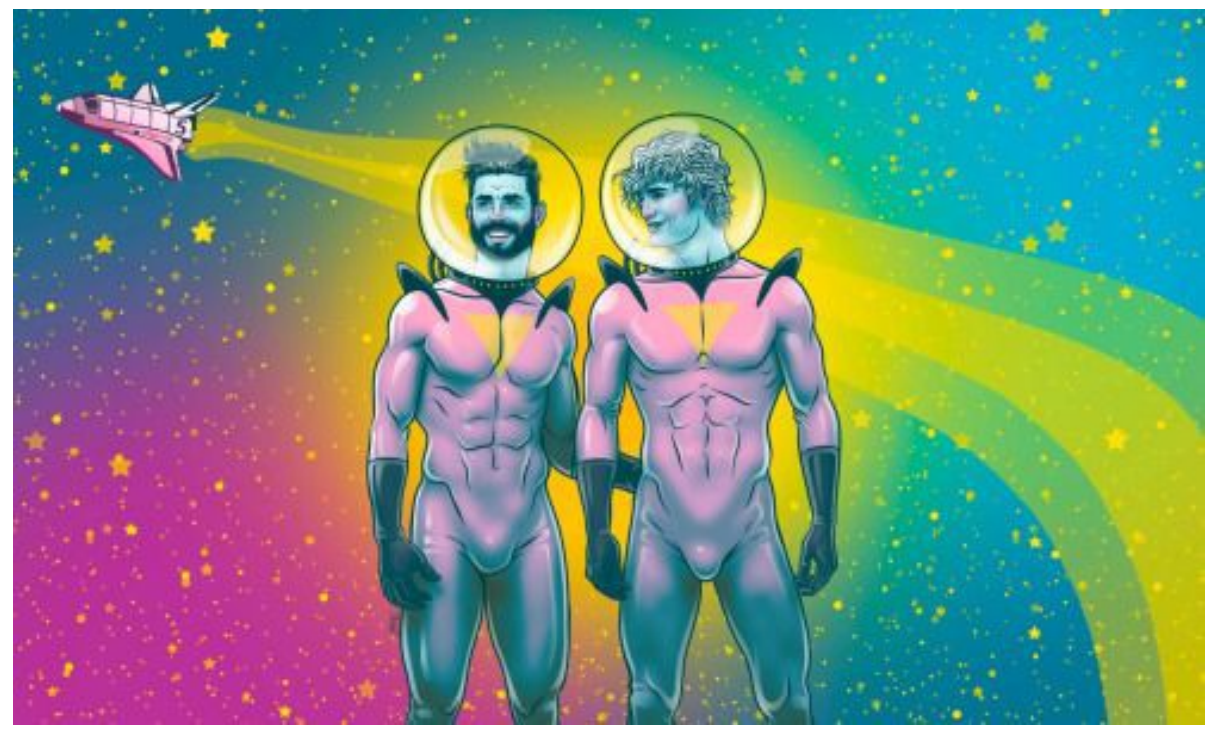

Figure 3: No idea what this is, but this is not what I mean by queering space-although it's also INCLUDED. (via Pinterist)

So in this way queer is also, if you'll permit it, a call-out to mad pride, Black power, sex workers, disability pride, Native pride, polyamory, abolitionist veganism, the elderly, imprisoned people, indigenous revolutionaries, impoverished people, anarchism, linguistic minorities, people living under occupation, and much more. It's all those ways that we are given no choice but to move in the between spaces of social, economic, and environmental life because the highways and sidewalks are full of other people whose identity, behavior, politics, and sensitivities aren't questioned all the time, and they won't budge.

In a sense, it's the old definition of queer as odd-because when they tell you that you don't belong, you don't fit it, you're unusual, then you're queer. It's that feeling that you're walking behind those five people walking side-by-side who won't let you pass because you're not one of them. Queer is radical, marginal, partial, torn, assembled, defiant, emergent selves — queer is also non-human - from stones and mountains to plants and 'invasive' species. I know, you're thinking: then what isn't queer? But, if you're asking that — the answer might be you. 


\section{Queer Lives in Orbit}

When I began writing this, there were nine people living in outer space from five countries, as best as I can determine they are all cis-gendered, heterosexual men from the dominant ethnic/racial group of their nation (please astronauts, correct me if I'm wrong here).

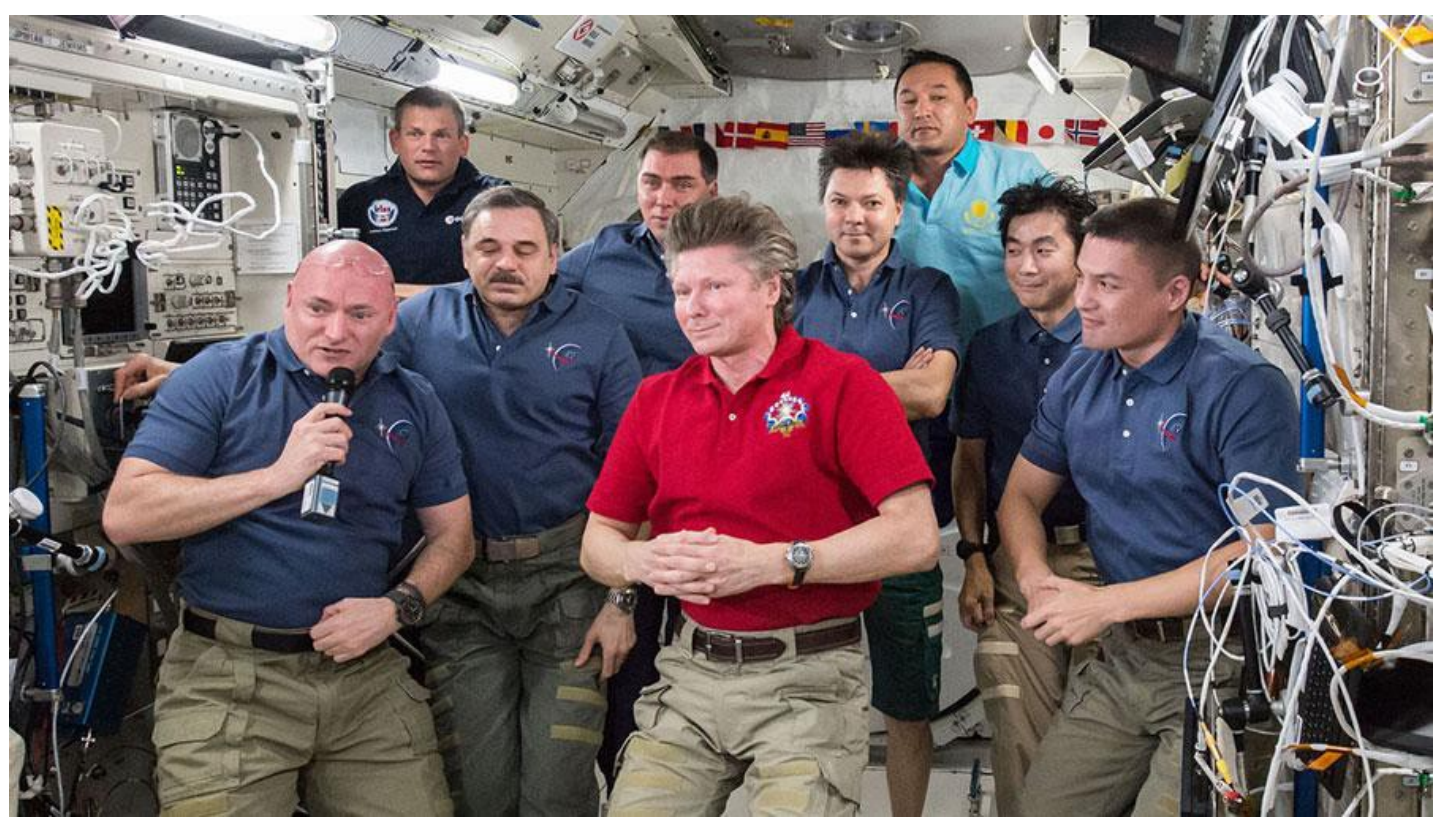

Figure 4: Crew of the International Space Station as of September 11, 2015 (via Twitter)

When the NASA space station motto declares "Off the Earth, For the Earth" we need to ask: which Earth? whose Earth? Beyond representation and tokenism which assumes "people of color" have a common racialized experience, we need to look to sciences where women, people of color, queer people, and others are fighting against great odds to participate in disciplines, be treated as colleagues, and have any visibility when we do.

Astronaut Sally Ride was queer, a fact that wasn't publicly revealed until after her death. Of 330 American astronauts, that means one has been identified as queer, and only after death. Part of this is certainly related to the fact that most astronauts came to the program through the military, which until recently didn't allow queer identity to exist openly. This begs further and obvious questions about what we are bringing to space, what kind of culture? What ideas, 
traditions, and practices? Are they exclusively military? And what does that mean for our futures in space?

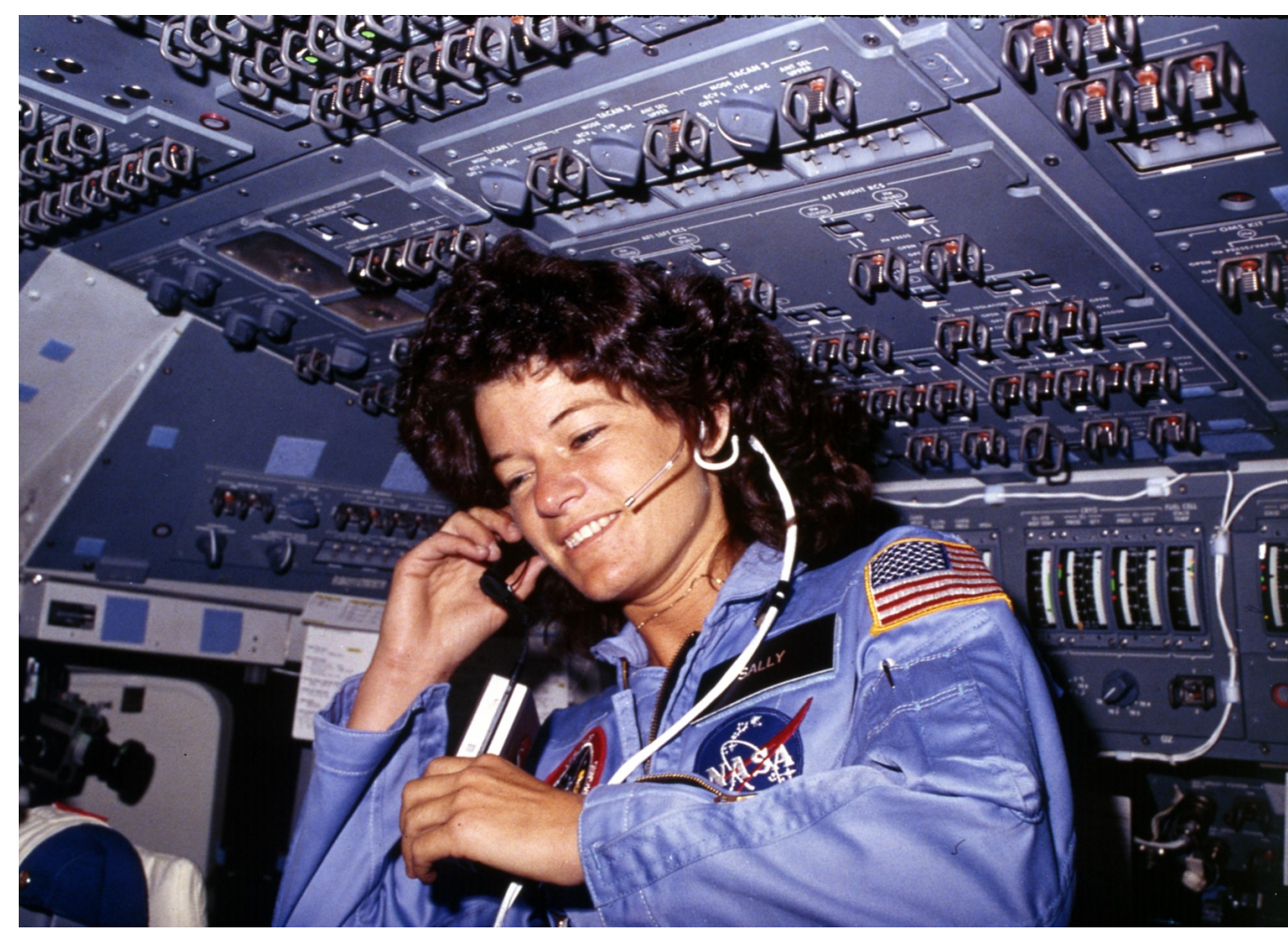

Figure 5: Sally Ride, the first American woman in space (wikipedia)

If expressions of personal identity are seen as running counter to "scientific neutrality," and are marginalized within science because of that - we have only to look to the history of science to see how un-neutral this normative notion of neutrality is. And how counterproductive this is for science and creativity (e.g., Kuhn on paradigms and scientific revolutions), and for honoring, respecting, and learning from indigenous knowledge and wisdom about the Earth and about space.

Why shouldn't expression, affect, sensitivity, and identity be a part of our movement into space? Aren't we, in some sense, coming out as a species onto a galactic or even universe-scale stage? And aren't we a diverse species, a colorful, even queer species with all of our material, emotional, architectural, technological accoutrement, and other fascinations? 


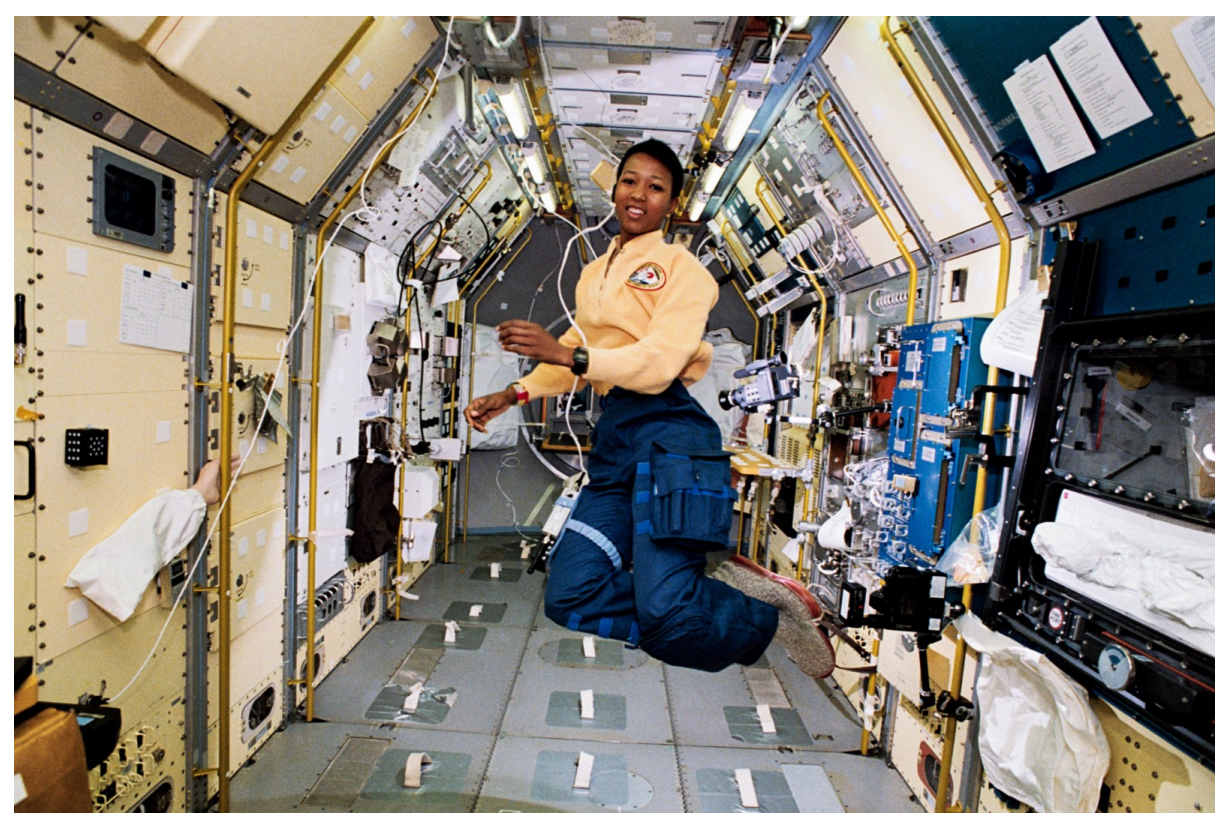

Figure 6: Physician and astronaut Dr. Mae Jemison, the first black woman in space.

Perhaps we've been out for a while as a species, since our television and radio transmissions started leaving Earth and heading out into interstellar space. Although those transmissions started with Hitler and are currently mostly about Donald Trump and Kim Davis. So, when we talk about sending messages to alien civilizations, we may also want to talk about what we're already saying.

Carl Sagan talked about, quite rightly, how similar we all are when seen from space. And in my field of anthropology there are many debates about what it means to look at universals vs. particulars. Is focusing on difference a problem for justice and universal rights? We need to think about similarities, many will argue, not difference. But sometimes the way we think about and promote similarity serves to erase differences — serves to whitewash, straightwash, genderwash, abilitywash people in an attempt to say that universal humanity is somehow represented by nine able-bodied, cis men floating in the International Space Station. But it isn't. 


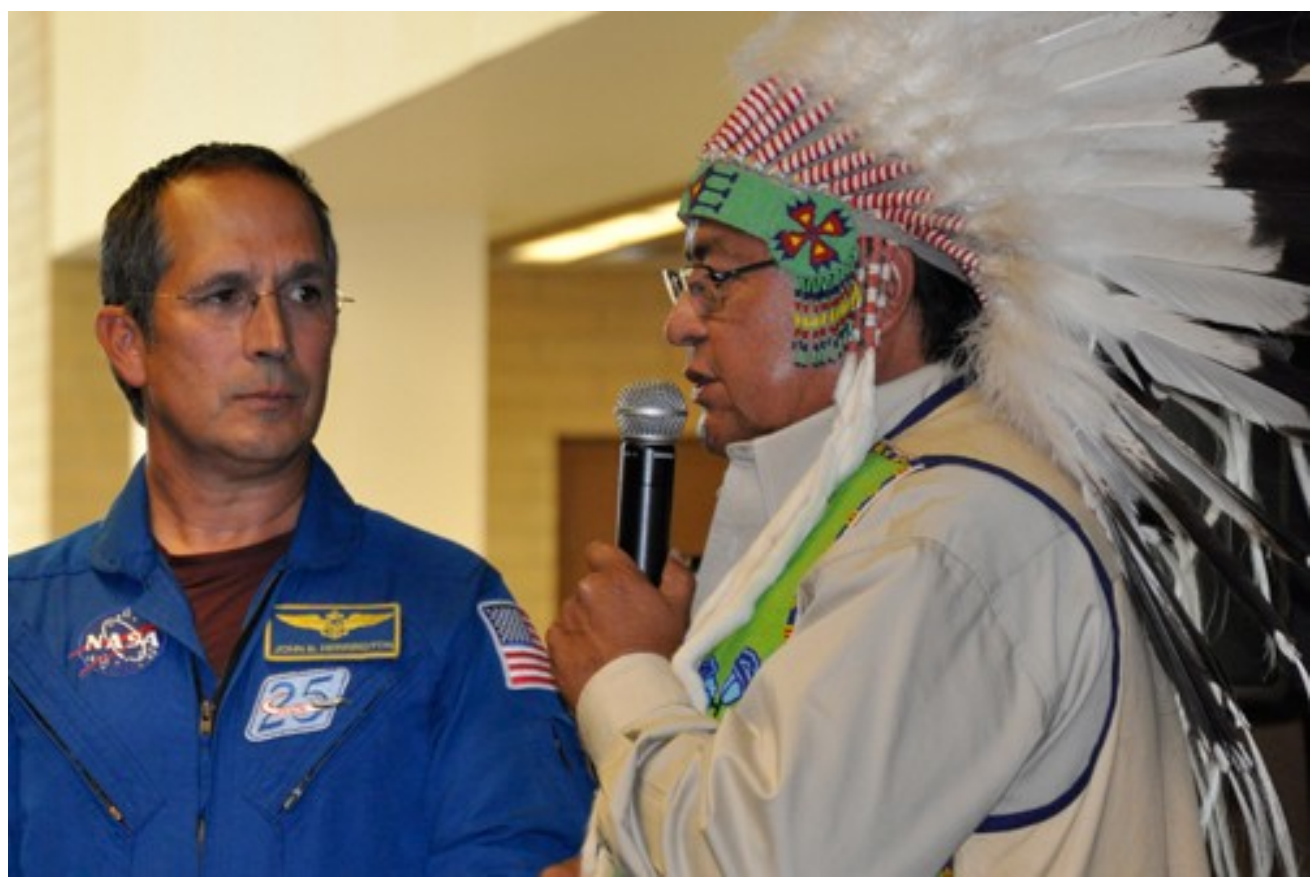

Figure 7: John Herrington (left) the first enrolled member of a Native American tribe to fly in space. (photo: Mount Royal University)

In Pale Blue Dot (1994), Carl Sagan wrote about the profound photograph of Earth taken from 3.7

billion miles away by the Voyager I spacecraft:

"Look again at that dot. That's here. That's home. That's us. On it everyone you love, everyone you know, everyone you ever heard of, every human being who ever was, lived out their lives. The aggregate of our joy and suffering, thousands of confident religions, ideologies, and economic doctrines, every hunter and forager, every hero and coward, every creator and destroyer of civilization, ever king and peasant, every young couple in love, every moth and father, hopeful child, inventor and explorer, every teacher of morals, every corrupt politician, every "superstar," every "supreme leader," every saint and sinner in the history of our species lived there — on a mote of dust suspended in a sunbeam."

But it's not just everyone you know and everyone you've heard of — it's everyone you don't know, everyone you've never heard of — all the marginalized, muffled, silenced, timid, and erased voices. All the many kinds of queer voices of Earth are also there, suspended in that sunbeam. 
Figure 8: Pale Blue Dot: Earth, the small dot in the top beam of light. Photo: NASA JP

This is why we have to stake a claim in the territory of space programs now. We need to add our voices, perspectives, plans, our cares. There isn't time to wait. We can't sit back and say: Space isn't urgently important, we should be looking at problems here on Earth. First of all, much of space science is looking at and working on problems here on Earth (from conflict, migration, and drought to climate change, deforestation, and more). Secondly, SpaceX, Boeing, and others are preparing new craft and taking humans into space now - and human technology is leaving the solar system. Perhaps it's not happening on the timeline you would prefer, but it's already happening and has been for decades, and they're pretty much doing it without us because for the most part we've decided that it isn't an area we want to engage in.

\section{De-colonizing Mars and Beyond}

When NASA received a signal from the Voyager 1 spacecraft in 2012, they called it "the sound of interstellar space" and marked the data as the moment human exploration crossed into the "space 
between stars" (NASA JPL n.d.). And while science and technology take us to the edges of the solar system and beyond, venture capital is planning how they can terraform new worlds - a neoliberal, capitalist project which has, of course, already stolen the phrase "Occupy." In response, we need to pre-emptively Occupy Mars while taking one of the many important lessons offered by indigenous people to the Occupy movement, and de-colonize Mars in the process. Which means injecting all of our queer and indigenous selves into the discussions about "settling" and "colonizing" Mars, into these plans to fundamentally change the surface of another planet, to reproduce Earth there.

Lisa Messeri, anthropologist and historian of science and technology, points out that if I use queering to mean something odd then something like Elon Musk's plan to nuke Mars, for example, might be seen as queer. Her excellent question about this and our chat on Twitter inspired me to clarify. I'm looking at Musk's terraforming language from the position that Mars is already queer. Remaking Mars in Earth's image, and uncritically assuming this is a great idea, is exactly the kind of process that queering works against. Nuking mars is an unqueer thing to do because it uses the model of razing and rebuilding, cutting it all down to make it possible to build a normative landscape on top of the ruins. We need to think about the ways that terraforming is not always a utopian idea, but can also be seen as a violent imposition of earthly normativity on landscapes elsewhere, a colonialization of existing queer-otherworld landscapes. 


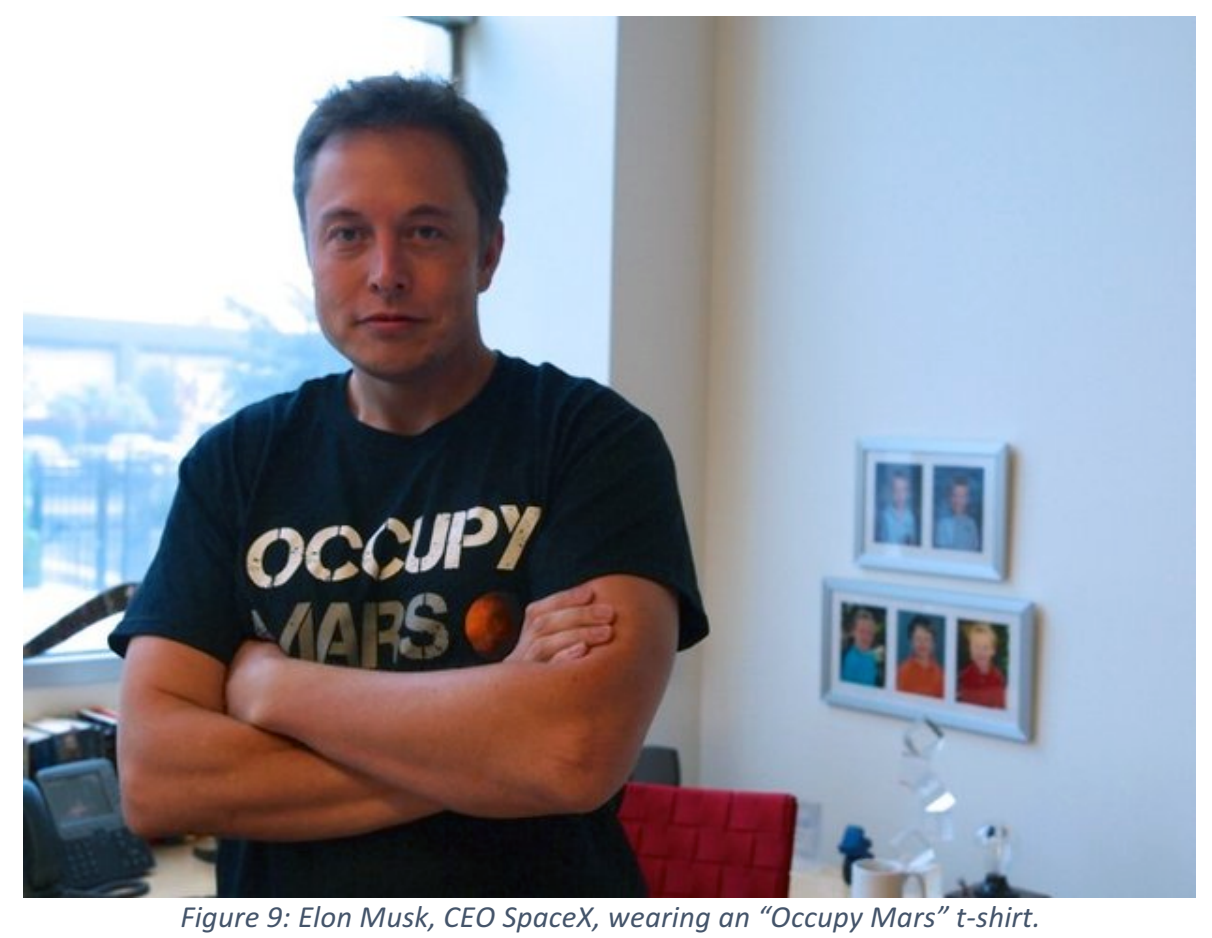

Biologist DNLee has asked exactly the kind of questions about Elon Musk's language and the discourse of Mars colonization that need to be asked:

"Who's version of humanity is being targeted for saving? And with the language of proposed interplanetary exploration and settlement using generous references to Christopher Columbus and New World Exploration and British Colonization and US American Manifest Destiny I was halted. I'm not on board for this type of science adventure. [...]

Why aren't other voices and perspectives at the table? How much is this conversation being controlled (framed, initiated, directed, routed) by capitalist and political interests of the (few) people at the table?"

Social scientists, activists, queer theorists and others need to ask themselves why they aren't asking these same questions (and joining those of us who are). Aside from a few examples, why have sociology, anthropology, and other social sciences and humanities left space science and exploration alone-why do they consistently fail to recognize the importance of work by those who do research in these areas?

Astrobiologist David Grinspoon critiqued this frontier mentality early on. Writing about the ethics of colonizing Mars in 2004, he notes that it's not only problematic for all of the above 
reasons, it also sets us up to reproduce the failures that come with thinking we can "conquer" a planet: "If we go to Mars with the idea that we can charge ahead and subdue a new world, our efforts are doomed [...] Mars does not belong to 'America,' nor to Earth, nor to human beings." As DNLee also points out, we're talking about widespread discourse with massive national and corporate funding to support a new era of colonization — isn't this a subject worth studying? Worth funding studies of? Worth getting involved in?

Space scientists are also working on the problem of how we can create the capabilities to visit another star, trying to figure out what we need to do now here on Earth to make that happen in 100 years. There are many interstellar projects, and it's a fascinating convergence of calls for longer-term thinking with planning and innovation in space science. When astronaut Mae Jemison describes 100 Year Starship — the project to achieve interstellar travel—she talks about creation stories, mythology, science fiction, and her hopes of "discovering a better version of ourselves in space" (100YSS 2014). We can join with visionaries like her to ensure that the "better version of ourselves" isn't a vision that ends up reproducing inequality, injustice, and oppressions from Earth out there in space. Space advocates like Jemison, the first black woman in space, will be leaders and allies in the quest to discover not only diversity in outer space but a better kind of diversityone that is aware of colonial histories, oppressive pasts and presents, ongoing violences here on Earth. A queer diversity. 


\section{Extraterrestrial Allies}

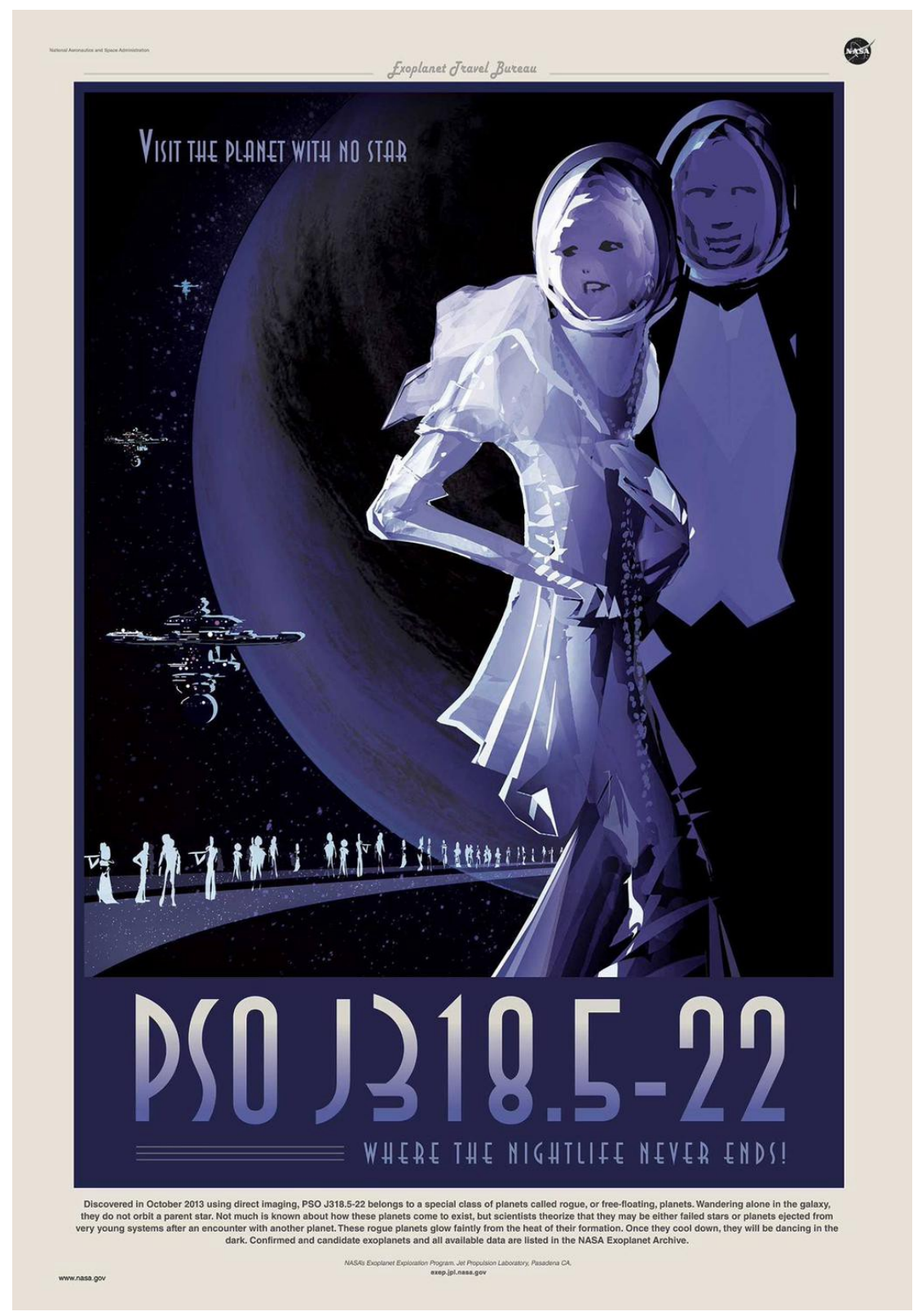

Figure 10: NASA's binary gender, heterosexual, nightlife in space poster.

The Interstellar Message Composition program at the SETI Institute (Search for Extraterrestrial Intelligence) advocates sending messages across the stars because "the universe beckons" (Shostak 2015). I happen to agree - there's a lot out there and if there wasn't life elsewhere, life that we might be able to talk to, it would certainly be "an awful waste of space" (as Carl Sagan wrote). 
And yet on the flip side when NASA releases vintage-style travel posters for newly discovered exoplanets featuring apparently white, binary-gendered, human couples, what message are we already sending both to Earth and beyond? That we expect the entire universe to look at act like us? Not all of us of course, just the elite few, the white, cis-gendered, heterosexual colonialist aristocracy in evening wear.

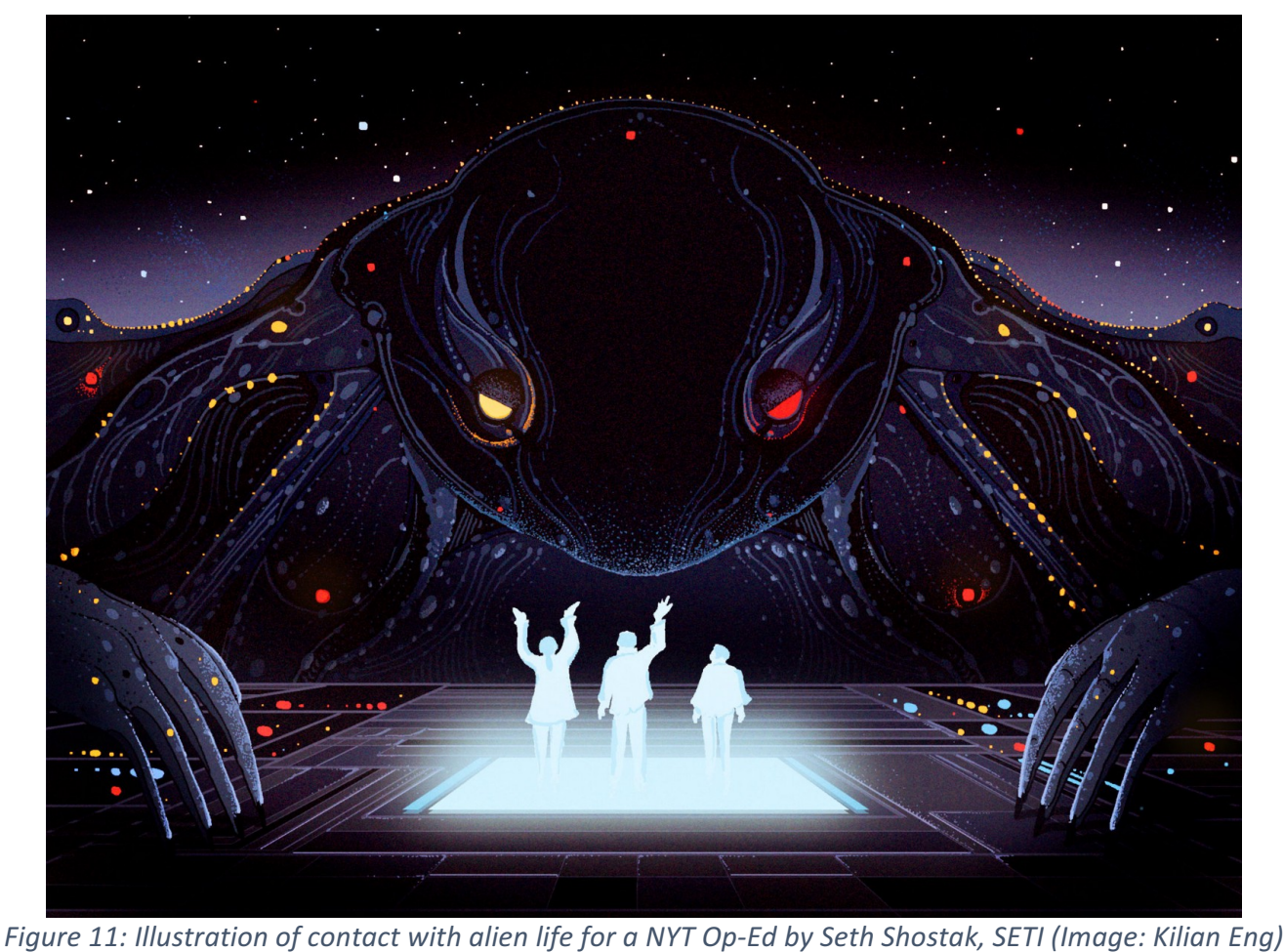

I realize this is supposed to be a light-hearted poster and it's "all in good fun"- — so even writing this critique makes me sound like I'm absolutely no fun. Quite the opposite, I think that poster is no fun! Why couldn't it depict other life? Like multi-gendered whale-cats dancing instead? Or humans who don't look like these two? Or something else, anything else-anything otherwise. Where is the imagination? Is this transposition of earthly aristocrats into space the best we can do? It's more evidence that we need queer visions of life elsewhere, of exoplanets, of alien worlds. We need more of what Haraway (2013), drawing on Marleen Barr (1992), calls "speculative fabulation." 
This isn’t just me saying "what about my ideas" or "include me in your game”- -because we've actually been there since the beginning. We've been imagining different worlds since we were born into a world where we often weren't wanted, didn't fit, and weren't following the rules by just being us. Queer folk, of all kinds, are at least united by having the most incredible skills in speculative fabulation - in envisioning every possible different future, bright and abysmal, and we do it because it's something we learned as a survival tactic and later honed as an art form.

\section{Generations of Queer Futures}

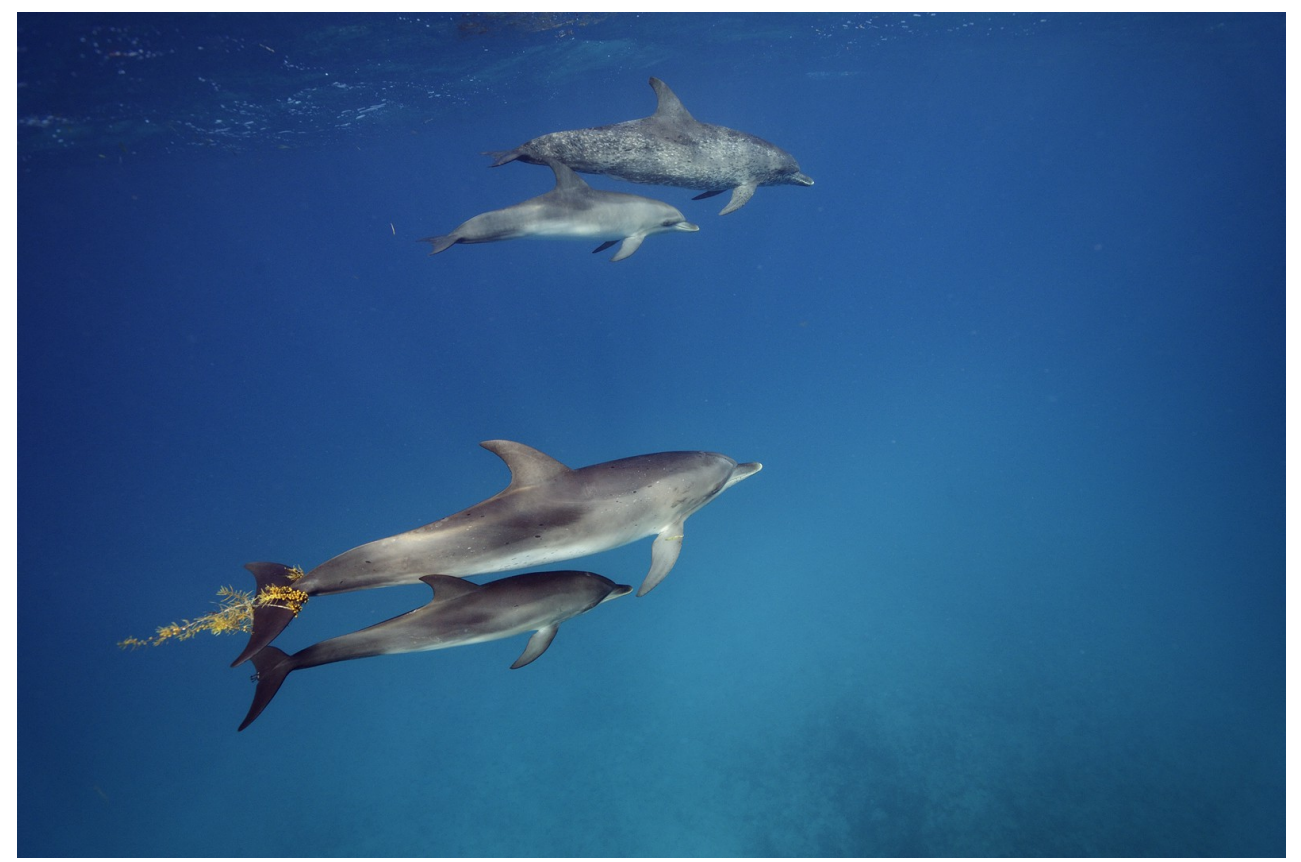

Figure 12: Intelligent residents of Earth who do not seem very interested in structurally oppressing one another.

Queerness has been discussed and debated in terms of the concept of "no future." When thinking about outer space, this could mean the freedom to disrupt normative futures-to remix, twist, adjust, tear, collage and queer the future. As anthropologist Naisargi Dave said about the idea: "I think queerness is precisely about what it means to pursue an orientation to the world, philosophically and politically, that doesn't need to reproduce itself in recognizable forms." Being 
freed from recognizable reproduction means opening up multiple possible futures, even queer futures.

When space science and fiction imagines a "generation ship," in which generations of crew live and die during a thousand-year voyage to a distant star (e.g., Ceyssens et al. 2012), we should ask how queer lives fit into these models of reproduction in space. In the recent Sci-Fi series Ascension (Williams 2014), queer people were excluded from a generation ship experiment. When one character said "homosexuals" or "anyone who avoids procreation" were left out because they're "superfluous" - a queer character responded: "We do tend to pop up where you least expect us...”

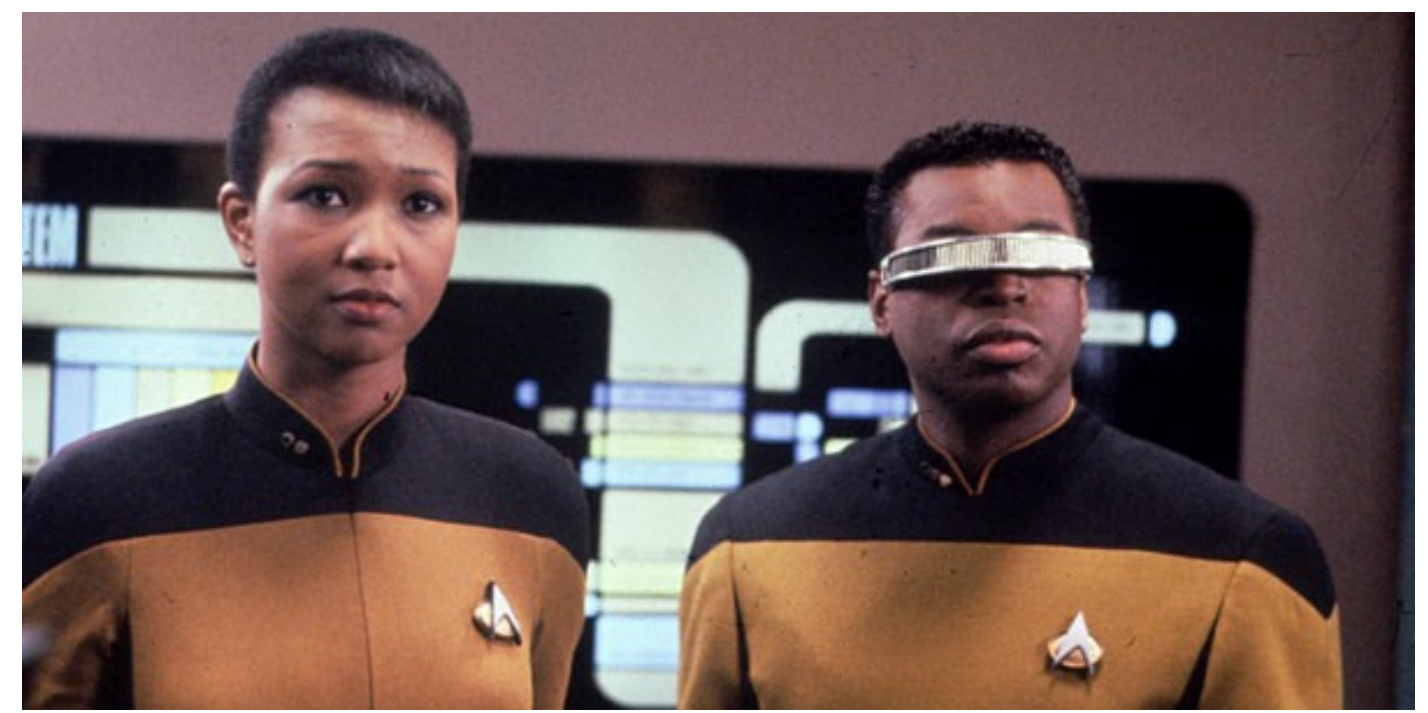

Figure 13: Astronaut Mae Jemison, the first Black woman in space, appearing as an extra on "Star Trek: The Next Generation" with Levar Burton.

If we consider science fiction as a "repository of modifiable futures" in science (Milburn 2010) then we can look at how to de-colonize that fiction and challenge the reproduction of normative futures through imagination and science. William Lempert has examined the way indigenous SciFi does this in his article "Decolonizing Encounters of the Third Kind: Alternative Futuring in Native Science Fiction Film" (2014), and a recently published collection of science fiction stories from social justice movements "Octavia’s Brood" (Imarisha and Brown 2015) reminds us that 
imagination, as philosopher John Dewey said, is our "common faith" (1934) — the shared human capacity to conceive of a better future and work together to make it a reality.

Science fiction is a "repository of modifiable futures" not only in science but also in society. Sci-Fi has been a site of racism, sexism, and xenophobia, as often as it has been the site of imagining better worlds and liberation (Haraway 2013). The recent battle over the Hugo awards demonstrates the lengths that some will go to to protect their visions of hostile, racist, misogynist, anti-queer, normative futures.

So what's next? We-all us queer, trans, disabled, black, native, etc. folk and more-we need to fight back, take back, de-colonize and re-imagine our futures in outer space, we need to pop up where they least expect us. 


\section{References Cited}

100YSS. 2014. Let's Make Human Interstellar Travel Capabilities a Reality Within the Next 100 Years. http://100yss.org/.

Anker, Peder. 2005. “The Ecological Colonization of Space.” Environmental History 10: 239-68.

Barr, Marleen S. 1992. Feminist Fabulation: Space/postmodern Fiction. Iowa City: University of Iowa Press.

Ceyssens, Frederik, Maarten Driesen, and Kristof Wouters. 2012. "On the Organisation of World Ships and Other Gigascale Interstellar Space Exploration Projects." Journal of the British Interplanetary Society 65: 134-39.

Grinspoon, David. 2003. Lonely Planets: The Natural Philosophy of Alien Life. New York: HarperCollins.

Hadfield, Chris. 2013. An Astronaut's Guide to Life on Earth. Toronto: Random House Canada.

Haraway, Donna Jeanne. 2013. "SF: Science Fiction, Speculative Fabulation, String Figures, So Far." Ada: A Journal of Gender, New Media, and Technology, no. 3 (November).

Imarisha, Walidah, and Adrienne Maree Brown, eds. 2015. Octavia's Brood: Science Fiction Stories from Social Justice Movements. Oakland, CA: A K Press.

McCray, Patrick. 2012. The Visioneers: How a Group of Elite Scientists Pursued Space Colonies, Nanotechnologies, and a Limitless Future. Princeton: Princeton University Press.

Milburn, Colin. 2010. "Modifiable Futures: Science Fiction at the Bench." Isis 101 (3): 560-69. doi:10.1086/652685.

NASA JPL. 2015. "Voyager Enters Interstellar Space-NASA Jet Propulsion Laboratory." Accessed April 5. www.jpl.nasa.gov/interstellarvoyager/.

Redfield, Peter. 2000. Space in the Tropics: From Convicts to Rockets in French Guiana. Berkeley: University of California Press.

Sagan, Carl. 1994. Pale Blue Dot: A Vision of the Human Future in Space. New York: Random House.

Shostak, Seth. 2013. "Are Transmissions to Space Dangerous?" International Journal of Astrobiology 12 (01): 17-20. doi:10.1017/S1473550412000274.

___ _ 2015. "Should We Keep a Low Profile in Space?" The New York Times, March 27. http://www.nytimes.com/2015/03/28/opinion/sunday/messaging-the-stars.html. 
Tyson, Neil deGrasse. 2012. Space Chronicles: Facing the Ultimate Frontier. Edited by Avis Lang. New York: W.W. Norton.

Vakoch, Douglas A. 2013. Astrobiology, History, and Society: Life Beyond Earth and the Impact of Discovery. Berlin; New York: Springer.

Valentine, David. 2012. "Exit Strategy: Profit, Cosmology, and the Future of Humans in Space." Anthropological Quarterly 85 (4): 1045-67.

Williams, Stephen. 2014. “Ascension.” Ascension. Canada, United States: CBC/Syfy.

Wright, Jason T., and Michael P. Oman-Reagan. "Visions of Human Futures in Space and SETI." International Journal of Astrobiology, 2017, 1-12. doi:10.1017/S1473550417000222. 